\title{
Prediction model and treatment of high-output ileostomy in colorectal cancer surgery
}

\author{
SHIKI FUJINO ${ }^{1}$, NORIKATSU MIYOSHI ${ }^{2}$, MASAYUKI OHUE ${ }^{2}$, YUSKE TAKAHASHI ${ }^{2}$, MASAYOSHI YASUI $^{2}$, \\ KEIJIRO SUGIMURA ${ }^{2}$, HIROHUMI AKITA ${ }^{2}$, HIDENORI TAKAHASHI ${ }^{2}$, SHOGO KOBAYASHI $^{2}$, \\ MASAHIKO YANO ${ }^{2}$ and MASATO SAKON ${ }^{2}$ \\ ${ }^{1}$ Department of Gastroenterological Surgery, Osaka University Graduate School of Medicine, Suita, Osaka 565-0871; \\ ${ }^{2}$ Department of Surgery, Osaka International Cancer Institute, Osaka 541-8567, Japan
}

Received March 17, 2017; Accepted May 24, 2017

DOI: $10.3892 /$ mco.2017.1336

\begin{abstract}
The aim of the present study was to examine the risk factors of high-output ileostomy (HOI), which is associated with electrolyte abnormalities and/or stoma complications, and to create a prediction model. The medical records of 68 patients who underwent colorectal cancer surgery with ileostomy between 2011 and 2016 were retrospectively investigated. All the patients underwent surgical resection for colorectal cancer at the Osaka Medical Center for Cancer and Cardiovascular Diseases (Osaka, Japan). A total of 7 patients with inadequate data on ileostomy output were excluded. Using a group of 50 patients who underwent surgery between 2011 and 2013, the risk of HOI was classified by a decision tree model using a partition platform. The HOI prediction model was validated in an additional group of 11 patients who underwent surgery between 2014 and 2016. Univariate analysis of clinical factors demonstrated that young age $(\mathrm{P}=0.003)$ and high white blood cell (WBC) count $(\mathrm{P}<0.001)$ after surgery were significantly correlated with HOI. Operative factors, such as surgical procedure, approach, operative time and blood loss, were not significantly correlated with HOI. Using these clinical factors, the risk of HOI was classified by statistical partition. In this model, three factors (gender, age and WBC on postoperative day 1) were generated for the prediction of HOI. The patients were classified into five groups, and HOI was observed in $0-88 \%$ of patients in each group. The area under the curve (AUC) was 0.838. The model was validated by an external dataset in an independent patient group, for which the AUC was 0.792. In conclusion, HOI patients were
\end{abstract}

Correspondence to: Dr Norikatsu Miyoshi, Department of Surgery, Osaka International Cancer Institute, 3-1 Otemae, Tyuou-ku, Osaka 541-8567, Japan

E-mail: miyosi-no@mc.pref.osaka.jp

Key words: colorectal cancer, ileostomy, high-output ileostomy, omega-3 fatty acid, eicosapentaenoic acid, partition, prediction model classified and an HOI prediction model was developed that may help clinicians in postoperative care.

\section{Introduction}

Surgery is an effective treatment for colorectal cancer (CRC) $(1,2)$, and certain procedures, such as low anterior resection and intersphincteric resection for lower rectal cancer, require an ileostomy to reduce the risk of severe anastomotic leakage (3-5). High-output ileostomy (HOI) is often observed and is accompanied by electrolyte abnormalities and/or stoma complications (6-8).

The aim of the present study was to determine the frequency and risk factors of $\mathrm{HOI}$ and to create a prediction model of HOI. Predicting HOI may be useful for perioperative treatment.

\section{Patients and methods}

Patients and data sets. A total of 68 consecutive patients who underwent surgery for colorectal cancer with ileostomy at the Osaka Medical Center for Cancer and Cardiovascular Diseases (Osaka, Japan) between 2011 and 2016 were retrospectively analyzed. HOI was defined by a maximum output of $>2,000 \mathrm{ml} /$ day and high output $(>1,000 \mathrm{ml} /$ day) lasting for $>3$ days (Fig. 1). A total of 7 patients for whom detailed data of output were unavailable were excluded (Fig. 2). Based on a group of 50 patients who underwent surgery between 2011 and 2013, a decision tree was used to develop a prediction model for HOI. Clinicopathological factors, such as patient sex, age, body mass index, tumor stage, procedure, operative approach, resection of other organs, operative time, blood loss, white blood cell (WBC) count on postoperative day (POD)1, and C-reactive protein levels on POD3, were assessed. These patients were included in a training set (TS) and classified by statistical partition. A total of 11 patients treated between 2014 and 2016 were included in a validation set (VS). The classification model was validated in this independent group. The present retrospective study was approved by the Osaka Medical Center for Cancer and Cardiovascular Diseases Ethics Committee, and written informed consent was obtained from all the patients. 
Table I. Clinicopathological factors in the training and validation sets.

\begin{tabular}{|c|c|c|c|}
\hline Factors & Training set $(n=50)$ & Validation set $(n=11)$ & P-value \\
\hline Gender (male/female) & $39 / 11$ & $7 / 4$ & 0.317 \\
\hline Age $^{\mathrm{a}}$, years (range) & $58(26-79)$ & $66(51-84)$ & 0.467 \\
\hline BMI, $\mathrm{kg} / \mathrm{m}^{2}$ (range) & $23(17-30)$ & $24(18-28)$ & 0.627 \\
\hline Procedure (ISR/LAR/total $/$ /others) & $23 / 24 / 2 / 1$ & $10 / 1 / 0 / 0$ & - \\
\hline Approach (laparoscopy\%open) & $9 / 41$ & $7 / 4$ & 0.002 \\
\hline Resection of other organs (present/absent) & $4 / 46$ & $3 / 8$ & 0.069 \\
\hline Operative time, $\min$ (range) & $412(263-733)$ & $521(402-592)$ & 0.006 \\
\hline Blood loss ${ }^{\mathrm{a}}, \mathrm{ml}$ (range) & $565(10-2300)$ & $275(50-580)$ & 0.022 \\
\hline WBC (POD1), $\left(\right.$ high $\left.^{\mathrm{d}} / \mathrm{WNL}^{\mathrm{e}}\right)$ & $25 / 25$ & $3 / 8$ & 0.171 \\
\hline CRP (POD3) ${ }^{\mathrm{a}}, \mathrm{mg} / \mathrm{dl}$ (range) & $11(3-25)$ & $6(4-28)$ & 0.364 \\
\hline $\mathrm{HOI}^{\mathrm{f}} /$ non-HOI ${ }^{\mathrm{g}}$ & $19 / 31$ & $3 / 8$ & 0.502 \\
\hline
\end{tabular}

Bold print indicates statistical significance. ${ }^{\mathrm{a} A n a l y s e d}$ as continuous variables. ${ }^{\mathrm{b}}$ Total colectomy. ${ }^{\mathrm{c}}$ Laparoscopic surgery and laparoscopy-assisted surgery. ${ }^{\mathrm{d}} \mathrm{WBC}$ count $>9,900$ cells $/ \mu 1$. ${ }^{\mathrm{e}}$ Normal $\mathrm{WBC} \geq 3,500$ and $\leq 9,900$ cells $/ \mu 1$. ${ }^{\mathrm{f}}$ The maximum ileostomy output was $>2,000 \mathrm{ml}$, and high output $(>1,000 \mathrm{ml})$ lasted for $>3$ days. ${ }^{9}$ Patients who did not have high output status. BMI, body mass index; ISR, intersphincteric resection; LAR, low anterior resection; POD, postoperative day; WBC, white blood cell; WNL, within normal limits; CRP, C-reactive protein; HOI, high-output ileostomy.

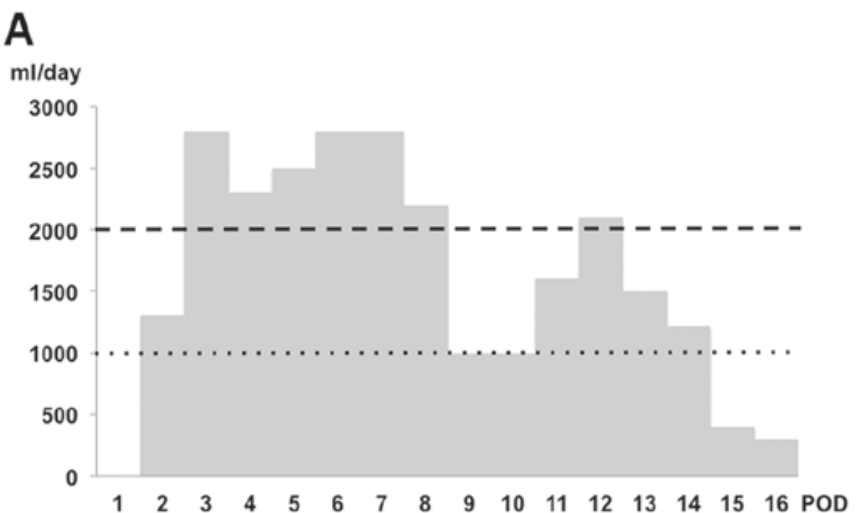

B

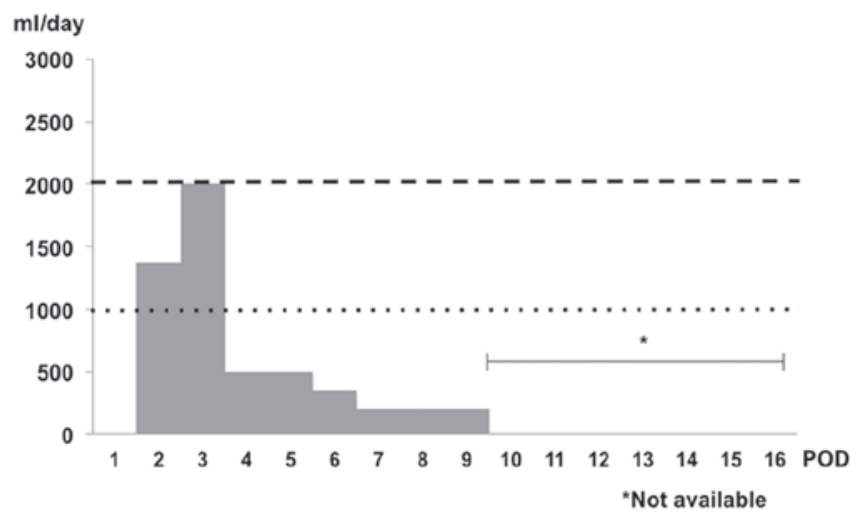

Figure 1. Clustered bar charts of ileostomy output. (A) A high-output ileostomy (HOI) case. The maximum output was $>2,000 \mathrm{ml} /$ day (dashed lines), and high output ( $>1,000 \mathrm{ml} /$ day, dotted lines) lasted for $>3$ days. (B) A non-HOI case. POD, postoperative day.

Statistical model creation. Categorical variables were analyzed using the Chi-squared test and continuous variables using the Mann-Whitney test. The log-rank test was used to analyze

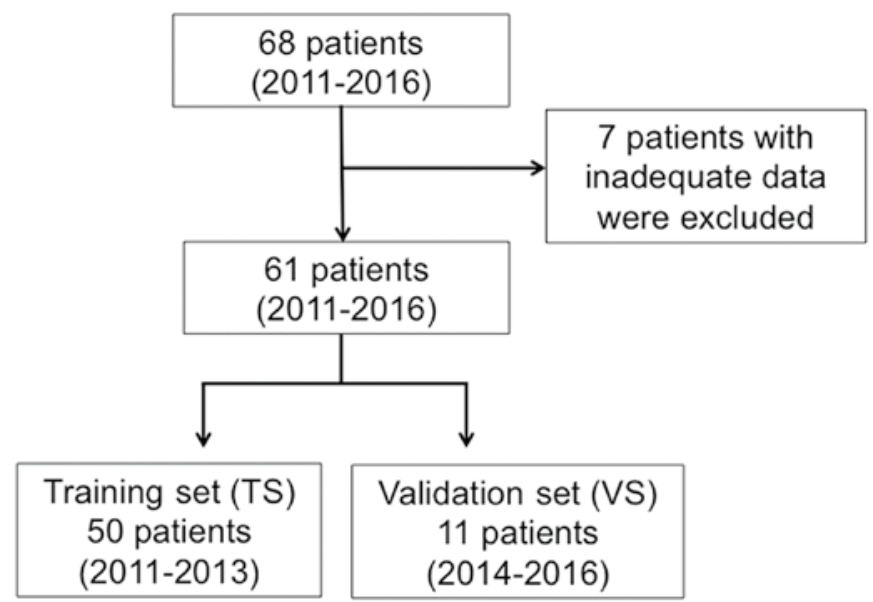

Figure 2. Schematic representation of patient selection and classification in the present study. A total of 68 surgically treated patients with ileostomy were enrolled; 7 patients were excluded as they lacked detailed ileostomy output data. A total of 61 patients were divided into two groups: 50 patients treated between 2011 and 2013 were included in the training set (TS), and 11 patients treated between 2014 and 2016 were included in the validation set (VS). A partition model was developed in the TS and validated in the VS.

differences in survival between the groups, and statistical significance was set at $\mathrm{P}<0.05$. All statistical analyses were performed using the JMP 11.0 statistical software program (SAS Institute, Cary, NC, USA). Classification for the risk of HOI was structured using JMP 11.0 (SAS Institute).

\section{Results}

Patient characteristics. The clinicopathological characteristics of all 61 patients (50 TS and 11 VS patients), are listed in Table I. HOI was observed in 19 patients in the TS and 3 patients in the VS. Recently, the increasing use of laparoscopic surgery 
Table II. Univariate analyses of HOI patients in the TS group.

\begin{tabular}{|c|c|c|c|}
\hline Variables & Non-HOI (31) & HOI (19) & P-value \\
\hline Gender (male/female) & $22 / 9$ & $17 / 2$ & 0.125 \\
\hline Age $^{\mathrm{a}}$, years (range) & $64(26-79)$ & $56(32-71)$ & 0.003 \\
\hline $\mathrm{BMI}, \mathrm{kg} / \mathrm{m}^{2}$ & $23.2(18.9-29.6)$ & $23.4(16.9-28.0)$ & 0.795 \\
\hline Tumor stage (I/II/III/IV/recurrence) & $9 / 7 / 11 / 2 / 1$ & $2 / 4 / 10 / 2 / 0$ & - \\
\hline Procedure (ISR/LAR/total /others) & $13 / 16 / 1 / 1$ & $10 / 8 / 1 / 0$ & - \\
\hline Approach (laparoscopyc/open) & $7 / 24$ & $2 / 17$ & 0.282 \\
\hline Resection of other organs (present/absent) & $2 / 29$ & $2 / 17$ & 0.606 \\
\hline Operative time, $\min$ (range) & $431(263-700)$ & $406(284-733)$ & 0.942 \\
\hline Blood loss ${ }^{\mathrm{a}}, \mathrm{ml}$ (range) & $480(30-1640)$ & $620(10-2300)$ & 0.555 \\
\hline WBC (POD1), (high $/$ WNL $\left.^{\mathrm{e}}\right)$ & $12 / 19$ & $13 / 6$ & 0.041 \\
\hline $\mathrm{CRP}(\mathrm{POD} 3)^{\mathrm{a}}, \mathrm{mg} / \mathrm{dl}$ (range) & $11.8(3.3-24.1)$ & $10.8(4.8-24.9)$ & 0.951 \\
\hline
\end{tabular}

Bold print indicates statistical significance. ${ }^{\mathrm{a} F a c t o r s}$ analysed as continuous variables. ${ }^{\mathrm{b}}$ Total colectomy. ${ }^{\mathrm{C}}$ Laparoscopic surgery and laparoscopy-assisted surgery. ${ }^{\mathrm{d}} \mathrm{WBC}$ count $>9,900$ cells $/ \mu 1$. ${ }^{\mathrm{e}}$ Normal $\mathrm{WBC}$ is $\geq 3,500$ and $\leq 9,900$ cells $/ \mu 1$. HOI, high-output ileostomy; TS, training set; BMI, body mass index; ISR, intersphincteric resection; LAR, low anterior resection; POD, postoperative day; WBC, white blood cell; WNL, within normal limits; CRP, C-reactive protein.

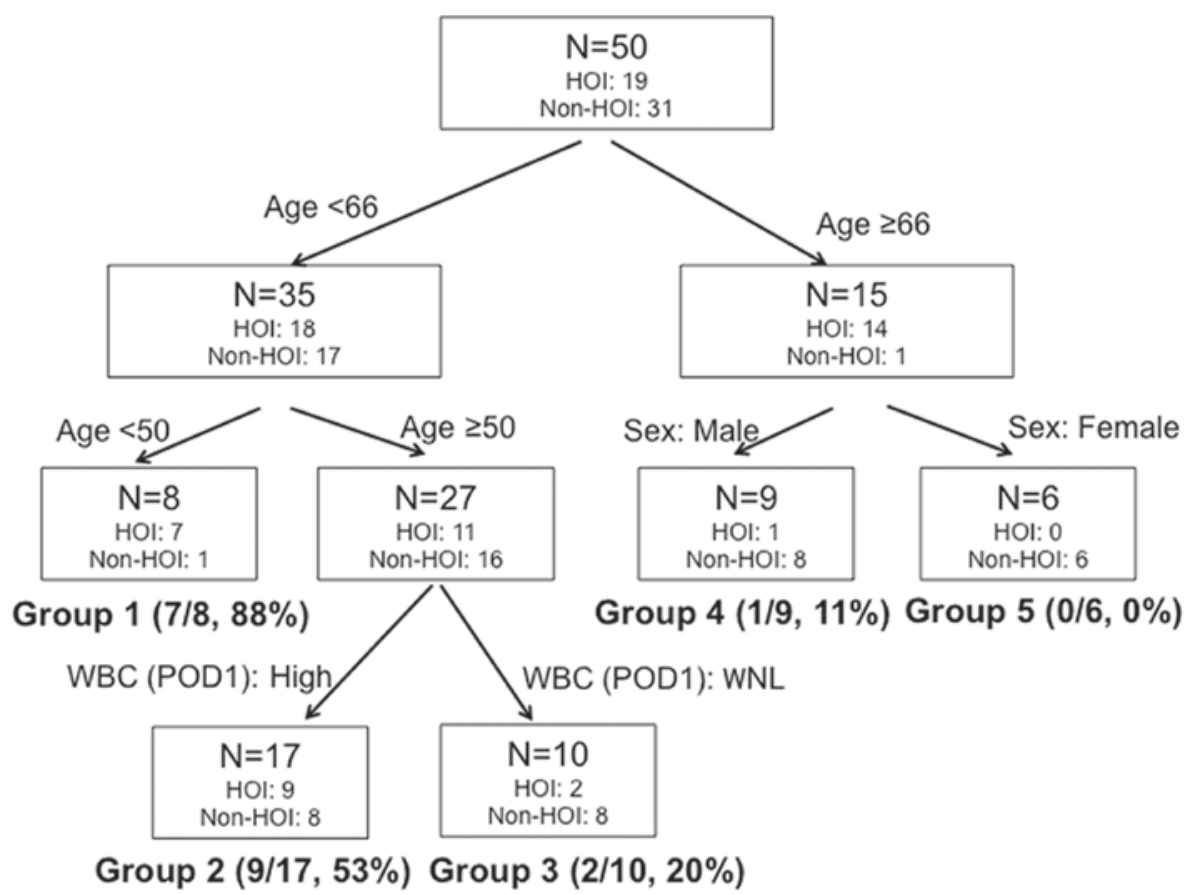

Figure 3. The partition that classified the HOI patients. The patients in the TS were classified into five groups using three factors, namely patient age, sex, and WBC on POD1. There were 7 patients (88\%) with HOI in group 1,9 patients (53\%) with HOI in group 2, 2 patients (20\%) with HOI in group 3, 1 patient (11\%) with HOI in group 4 , and 0 patients (0\%) with HOI in group 5. HOI, high-output ileostomy; TS, training set; POD, postoperative day; WBC, white blood cell; WNL, within normal limits.

has led to more laparoscopic surgeries being performed in the VS compared with the TS $(\mathrm{P}=0.002)$. The operative time was longer $(\mathrm{P}=0.006)$ and blood loss was lower $(\mathrm{P}=0.022)$ in the TS.

Univariate analysis of clinicopathological factors of $\mathrm{HOI}$ in the TS. The results of the univariate analysis of the clinicopathological factors of HOI in the TS are shown in Table II. Young age $(\mathrm{P}=0.003)$ and high WBC count on POD1 $(\mathrm{P}=0.041)$ were significant factors in HOI. Operative factors, such as surgical procedure, approach, operative time and blood loss, were not found to be significant. Using these clinical factors, the risk of HOI was classified using JMP 11.0 Partition (SAS Institute). In this model, three factors (gender, age and WBC on POD1) were generated for the prediction of HOI. The results generated by the statistical analysis using the clinical factors in relation to HOI are shown Fig. 3. The patients were classified into five groups. The rate of $\mathrm{HOI}$ ranged from 0 to $88 \%$ in each 
Table III. Clinicopathological factors in the TS and EPA groups.

\begin{tabular}{|c|c|c|c|}
\hline Factors & TS (non-EPA) group $(n=50)$ & EPA group $(n=10)$ & P-value \\
\hline Gender (male/female) & $39 / 11$ & $8 / 2$ & 0.889 \\
\hline Age $^{\mathrm{a}}$, years (range) & $58(26-79)$ & $54(44-78)$ & 0.326 \\
\hline $\mathrm{BMI}, \mathrm{kg} / \mathrm{m}^{2}$ (range) & $23(17-30)$ & $22(12-27)$ & 0.083 \\
\hline Procedure (ISR/LAR/total ${ }^{\mathrm{b}}$ /others) & $23 / 24 / 2 / 1$ & $8 / 0 / 2 / 0$ & - \\
\hline Approach (laparoscopycopen) & $9 / 41$ & $4 / 6$ & 0.123 \\
\hline Resection of other organs (present/absent) & $4 / 46$ & $0 / 10$ & 0.335 \\
\hline Operative time, min (range) & $412(263-733)$ & $532(373-778)$ & 0.011 \\
\hline Blood loss ${ }^{\mathrm{a}}, \mathrm{ml}$ (range) & $565(10-2300)$ & $418(50-580)$ & 0.620 \\
\hline WBC (POD1), (high $\left.{ }^{\mathrm{d}} / \mathrm{WNL}^{\mathrm{e}}\right)$ & $25 / 25$ & $5 / 5$ & 1.000 \\
\hline CRP (POD3) ${ }^{\mathrm{a}}, \mathrm{mg} / \mathrm{dl}$ (range) & $11(3-25)$ & $11(2-17)$ & 0.152 \\
\hline $\mathrm{HOI}^{\mathrm{f}} /$ non-HOI ${ }^{\mathrm{g}}$ & $19 / 31$ & $1 / 9$ & 0.086 \\
\hline
\end{tabular}

Bold print indicates statistical significance. ${ }^{\mathrm{a}}$ Factors analysed as continuous variables. ${ }^{\mathrm{b}}$ Total colectomy. ${ }^{\mathrm{c}}$ Laparoscopic surgery and laparoscopy-assisted surgery. ${ }^{\mathrm{d}} \mathrm{WBC}$ count $>9,900$ cells $/ \mu 1$. ${ }^{\mathrm{e}}$ Normal $\mathrm{WBC}$ is $\geq 3,500$ and $\leq 9,900$ cells $/ \mu 1$. ${ }^{\mathrm{f}}$ The maximum ileostomy output was $>2,000 \mathrm{ml}$, and high output $(>1,000 \mathrm{ml})$ lasted for $>3$ days. ${ }^{9}$ Patients who did not have high output status. TS, training set; EPA, eicosapentaenoic acid; BMI, body mass index; ISR, intersphincteric resection; LAR, low anterior resection; POD, postoperative day; WBC, white blood cell; WNL, within normal limits; CRP, C-reactive protein; HOI, high-output ileostomy.

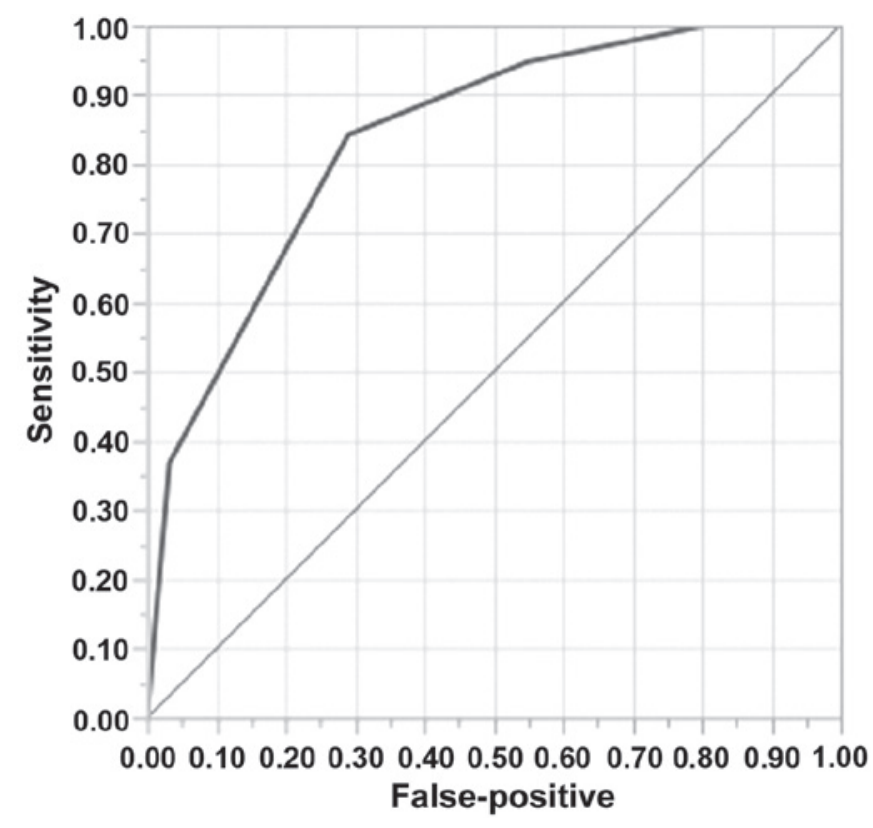

Figure 4. Receiver operating characteristic curve of the partition. The area under the curve was 0.838 in the training set.

group, and this model was able to distinguish the high-risk group of HOI. The area under the curve (AUC) was 0.838 in the TS (Fig. 4). The model was validated by an external dataset in an independent patient group between 2014 and 2016, with an AUC of 0.792.

\section{Discussion}

Loperamide and codeine phosphate are widely prescribed to treat non-perioperative HOI $(9,10)$. Although these pharmacological agents reduce ileostomy output, they are not commonly used in perioperative $\mathrm{HOI}$ treatment, as the perioperative use of opioids has been shown to increase the risk of ileus (11). It has been reported that Clostridium difficile (C. difficile) infection often occurs in HOI (12); however, $C$. difficile was not detected in our cases (data not shown).

High WBC after surgery was associated with $\mathrm{HOI}$ in the present study, and inflammation was reported to be associated with severe diarrhea from bacterial infection and inflammatory bowel disease $(13,14)$. Inflammation is a protective host response to foreign antigenic challenge or tissue injury; however, an overactive immune response may lead to loss of tissue structure as well as function. The omega- 3 fatty acid eicosapentaenoic acid (EPA) was reported to reduce the bowel inflammation that results in diarrhea $(15,16)$. EPA counter-regulates leukocyte-mediated tissue injury and proinflammatory gene expression (15). It has been reported that nutritional management is important in HOI treatment $(7,8)$. Recent studies have reported that ProSure ${ }^{\mathrm{TM}}$ (Abbot Japan Co., Ltd, Tokyo, Japan), an EPA-containing supplement, affects the nutritional status and quality of life in advanced cancer patients $(17,18)$. ProSure ${ }^{\mathrm{TM}}$ was introduced in postoperative nutritional management and the ileostomy output was examined. An additional 12 consecutive patients were enrolled in the EPA group managed by ProSure ${ }^{\mathrm{TM}}$. The maximum oral ProSure $^{\mathrm{TM}}$ intake was set at $480 \mathrm{ml}$ (EPA, $2 \mathrm{~g}$ ) and it was freely consumed by each patient after surgery. Two patients who could not consume the drink due to its taste were excluded. The median ProSure ${ }^{\mathrm{TM}}$ intake was $300 \mathrm{ml}$ (range, 240-480 ml) and the median EPA intake was 1,320 mg (range, 1056-2112 mg). The clinicopathological factors of the EPA group are shown in Table III. The ileostomy output did not differ significantly between the TS and EPA groups, but the rate of HOI was lower in the EPA group (10\%) compared with that in the non-EPA group. Thus, nutritional management with EPA may help reduce the risk of HOI in patients according to the prediction model. 
In summary, patients with HOI were classified using a prediction model. This model may provide clinicians with useful information for postoperative care.

\section{References}

1. Glimelius B, Tiret E, Cervantes A and Arnold D; ESMO Guidelines Working Group: Rectal cancer: ESMO clinical practice guidelines for diagnosis, treatment and follow-up. Ann Oncol 24 (Suppl 6): vi81-vi88, 2013.

2. Watanabe T, Itabashi M, Shimada Y, Tanaka S, Ito Y, Ajioka Y, Hamaguchi T, Hyodo I, Igarashi M, Ishida $\mathrm{H}$, et al: Japanese Society for Cancer of the Colon and Rectum (JSCCR) Guidelines 2014 for treatment of colorectal cancer. Int J Clin Oncol 20 207-239, 2015.

3. Matthiessen P, Hallböök O, Rutegård J, Simert G and Sjödahl R: Defunctioning stoma reduces symptomatic anastomotic leakage after low anterior resection of the rectum for cancer: A randomized multicenter trial. Ann Surg 246: 207-214, 2007.

4. Veenhof AA, van der Peet DL, Meijerink WJ and Cuesta MA: Defunctioning stoma reduces symptomatic anastomotic leakage after low anterior resection of the rectum for cancer: A randomized multicenter trial. Ann Surg 247: 718-720, 2008.

5. Katsuno H, Shiomi A, Ito M, Koide Y, Maeda K, Yatsuoka T, Hase K, Komori K, Minami K, Sakamoto K, et al: Comparison of symptomatic anastomotic leakage following laparoscopic and open low anterior resection for rectal cancer: A propensity score matching analysis of 1014 consecutive patients. Surg Endosc 30 2848-2856, 2016.

6. Baker ML, Williams RN and Nightingale JM: Causes and management of a high-output stoma. Colorectal Dis 13: 191-197, 2011.

7. Arenas Villafranca JJ, López-Rodriguez C, Abilés J, Rivera R, Gándara Adán N and Utrilla Navarro P: Protocol for the detection and nutritional management of high-output stomas. Nutr J 14: 45, 2015.

8. Rostami K and Al Dulaimi D: Elemental diets role in treatment of high ileostomy output and other gastrointestinal disorders. Gastroenterol Hepatol Bed Bench 8: 71-76, 2015.

9. Newton CR: Effect of codeine phosphate, Lomotil, and Isogel on iileostomy function. Gut 19: 377-383, 1978.
10. King RF, Norton T and Hill GL: A double-blind crossover study of the effect of loperamide hydrochloride and codeine phosphate on ileostomy output. Aust N Z J Surg 52: 121-124, 1982.

11. Artinyan A, Nunoo-Mensah JW, Balasubramaniam S, Gauderman J, Essani R, Gonzalez-Ruiz C, Kaiser AM and Beart RW Jr: Prolonged postoperative ileus-definition, risk factors, and predictors after surgery. World J Surg 32: 1495-1500, 2008.

12. Gaertner WB, Madoff RD, Mellgren A, Kwaan MR and Melton GB: Postoperative diarrhea and high ostomy output impact postoperative outcomes after elective colon and rectal operations regardless of Clostridium difficile infection. Am J Surg 210: 759-765, 2015.

13. Greenberg DE, Jiang ZD, Steffen R, Verenker MP and DuPont HL: Markers of inflammation in bacterial diarrhea among travelers, with a focus on enteroaggregative Escherichia coli pathogenicity. J Infect Dis 185: 944-949, 2002.

14. Neurath MF: Cytokines in inflammatory bowel disease. Nat Rev Immunol 14: 329-342, 2014.

15. Arita M, Yoshida M, Hong S, Tjonahen E, Glickman JN, Petasis NA, Blumberg RS and Serhan CN: Resolvin E1, an endogenous lipid mediator derived from omega-3 eicosapentaenoic acid, protects against 2,4,6-trinitrobenzene sulfonic acid-induced colitis. Proc Natl Acad Sci USA 102: 7671-7676, 2005.

16. Konuma K, Itoh M, Suganami T, Kanai S, Nakagawa N, Sakai T, Kawano H, Hara M, Kojima S, Izumi Y and Ogawa Y: Eicosapentaenoic acid ameliorates non-alcoholic steatohepatitis in a novel mouse model using melanocortin 4 receptor-deficient mice. PLoS One 10: e0121528, 2015.

17. Read JA, Beale PJ, Volker DH, Smith N, Childs A and Clarke SJ: Nutrition intervention using an eicosapentaenoic acid (EPA)-containing supplement in patients with advanced colorectal cancer. Effects on nutritional and inflammatory status: A phase II trial. Support Care Cancer 15: 301-307, 2007.

18. Sánchez-Lara K, TurcottJG,Juárez-HernándezE,Nuñez-ValenciaC, Villanueva G, Guevara P, De la Torre-Vallejo M, Mohar A and Arrieta O: Effects of an oral nutritional supplement containing eicosapentaenoic acid on nutritional and clinical outcomes in patients with advanced non-small cell lung cancer: Randomised trial. Clin Nutr 33: 1017-1023, 2014. 